\title{
VACCEOS ¿IDENTIDAD DE PASADO O DE FUTURO?
}

\author{
Vacceans, Past or future identity? \\ Rosalía HERNÁNDEZ García \\ Universidad Complutense de Madrid \\ E-mail: rosaliahgsal@hotmail.com
}

Fecha de recepción: 6-III-2011

Fecha de aceptación: 26-III-2011

\begin{abstract}
Resumen: Actualmente, cuando se habla de vacceos, los debates se centran en la discusión de sus límites geográfico-culturales y la definición de su identidad, aunque teniendo presente que la vida de este pueblo se agotó con la asimilación romana. Una reflexión más profunda nos hace preguntarnos si esta identidad ha sobrevivido de alguna forma hasta nuestros días: conceptos como el debatido "colectivismo vacceo" fueron utilizados para apoyar diversos discursos ideológicos, además no debemos olvidar la asimilación popular de este pueblo en la actualidad a través de grupos de rugby ("vacceos cavaliers"), asociaciones, marcas comerciales, etc. El objetivo de esta intervención es estudiar de qué forma los diversos elementos que definen o definían dicha cultura han sido utilizados a lo largo de la historia reciente.
\end{abstract}

Palabras clave: vacceos, identidad, asimilación conceptual, historia reciente.

ABSTRACT: Nowadays, when talking about the vaccei, discussions focus on the debate of geographic and cultural boundaries and on the definition of their identity, but bearing in mind that the life of this people was sold for thousands of years by the Roman assimilation. A further reflection makes us wonder if this identity has survived to some extension up to the present: concepts such as the controversial "vaccean collectivism" were used to support various ideological discourses, furthermore it shouldn't be missed the popular uptake of this ancient people today through Rugby's team (vacceos cavaliers), partnerships, trademarks and wines with the name of vaccei, among many others. The aim of this paper is to study how the various factors that determine or define that culture have been used over recent history.

Keywords: vacceoi, identity, conceptual assimilation, recent history. 


\section{INTRODUCCIÓN}

Parece evidente que al hablar de un pueblo como los vacceos sea obligatorio trasladarnos a la antigüedad para intentar comprender sus características; numerosas publicaciones intentan explicarnos cómo fueron, con quién se relacionaron, quiénes componían sus elites y cuáles eran los elementos propios que les diferenciaban de otras culturas, sin embargo, algunos de sus elementos son recuperados en la actualidad con un objetivo concreto. Cuáles son estos elementos y la utilización de los mismos serán el centro de nuestra exposición.

\section{2. ¿QUUIÉNES SON LOS VACCEOS?}

Los vacceos ${ }^{1}$, los habitantes de la cuenca central del Duero durante la Edad del Hierro y bajo dominio romano, se definen por un sistema de poblamiento basado en los oppida, centros urbanos con numerosa población y una importante articulación interna, habitualmente fortificados; la distribución de este hábitat la encontramos en torno a los denominados "vacios vacceos", los cuales podrían demarcar las fronteras territoriales ${ }^{2}$.

Existiría una organización política de gran complejidad en torno a estos núcleos de población, aunque nos es muy desconocida. Se constatan notables diferencias sociales y formas de subordinación, muy claras en las necrópolis de cremación inmediatas a los oppida.

En cuanto a la economía, nos encontramos con una agricultura muy desarrollada tanto de secano como de regadío, además de huertas, árboles frutales y prados. Será Diodoro de Sicilia $(\mathrm{V}, 34,3)$ el que nos indique la existencia de un sistema agrario que se ha dado en denominar "colectivismo vacceo", sin embargo, las últimas teorías indican que estaríamos ante una situación excepcional. La ganadería tiene un papel muy importante, sobre todo la ovina y la caballar, siendo considerados bienes de riqueza fundamental que darían lugar tanto a intercambios comerciales como a

1 Para una información más completa sobre las características de los vacceos consúltense: DELIBES DE CASTRO, G., ROMERO CARNICERO, F. y MORALES MUÑIZ, A., (Eds.), (1995); Arqueología y Medio ambiente. El primer milenio a.C. en el Duero Medio. (Junta de Castilla y León). Valladolid. ; ROMERO CARNICERO, F., SANZ MÍNGUEZ, C. y ESCUDERO NAVARRO, Z. (eds.), (1993); Arqueología vaccea. Estudios sobre el mundo prerromano en la cuenca media del Duero. (Junta de Castilla y León). Valladolid. ; SANZ MÍNGUEZ, C. y VELASCO VÁZQUEZ, J. (eds.) (2003): Pintia. Un oppidum en los confines orientales de la región vaccea. Investigaciones arqueológicas vacceas, romanas y visigodas (1999-2003). (Universidad de Valladolid). Valladolid.

2 Para una información más detallada consultar: SACRISTAN DE LAMA, José David (1989), "Vacíos vacceos" en Arqueología Espacial (Ejemplar dedicado a Fronteras), no 13, pp. $77-88$. 
luchas entre pueblos fronterizos que llevarían a cabo razæias para conseguir dicha riqueza. No debemos olvidar la gran importancia de la caza.

También vemos un gran desarrollo de la artesanía: la alfarería, la confección de sagi (mantas de lana), la reparación de sus herramientas y la existencia de una orfebrería local de gran importancia; la cerámica característica será a torno con decoración geométrica; todos ellos nos remiten a la existencia de intercambios comerciales, para la cual es necesaria la existencia de mercados urbanos, todavía no localizados arqueológicamente. Tendrían unas vías de comunicación claramente asentadas, aunque de difícil constatación arqueológica. Estas serán utilizadas por Roma en la conquista y el trazado de las posteriores calzadas romanas.

Los vacceos nunca acuñaron moneda, los intercambios comerciales se realizaban a través del trueque, de la utilización de objetos (laminillas de plata, joyas...) como moneda con un patrón y peso identificables, además del atesoramiento de moneda de otras procedencias.

En cuanto a la religión, podemos verificar la existencia de espacios al aire libre, cuevas, fuentes o aguas manantiales; edificaciones dentro de los poblados además de la posible existencia de santuarios urbanos, aunque este último sin constatación arqueológica. La gran complejidad de la sociedad parece indicar la existencia de una organización sacerdotal encargada de los cultos, aunque no tenemos constancia de ella. El ritual funerario habitualmente practicado era la cremación, sin embargo, los niños de corta edad serían inhumados y los guerreros muertos en combate serían expuestos a los buitres, animales sagrados; esta diferenciación se debe fundamentalmente a la diferencia de status dentro de la sociedad del individuo muerto; esta diferencia también la encontramos en las necrópolis por la gran diversidad de los ajuares y ofrendas que acompañan a los difuntos, lo que nos indica la existencia de una sociedad claramente jerarquizada y compleja.

\section{VACCEOS ¿IDENTIDAD DE PASAdo O DE FUtURo?}

En la actualidad se están realizando numerosas investigaciones sobre el pueblo vacceo, sin embargo, la escasez de excavaciones arqueológicas sistemáticas en el solar del antiguo territorio vacceo complica la situación. El yacimiento de Las Quintanas, localizado en los límites de las poblaciones de Padilla y Pesquera de Duero e identificado con la antigua ciudad de Pintia, de gran importancia para el avance de estudios vacceos, es el único que se excava con regularidad y el que nos va suministrando, año tras año, nueva información sobre este pueblo ${ }^{3}$; sin embargo, la centralización de las

3 En los últimos años han salido a la luz diversas monografías del yacimiento pintiano cómo SANZ MÍNGUEZ, C. y VELASCO VÁZQUEZ, J. (eds.) (2003): Pintia. Un oppidum en los confines orientales de la región vaccea. Investigaciones arqueológicas vacceas, romanas y visigodas (1999-2003). (Universidad de Valladolid). Valladolid; SANZ MÍNGUEZ, C. y ROMERO CARNICERO, F. (eds.) (2005): Pintia cotidiana y simbólica. (Universidad de Valladolid. Centro 
investigaciones en el yacimiento pintiano junto con la extrapolación de los datos a otras zonas vacceas provocan que Pintia se convierta en un arma de doble filo. A pesar de todo debemos alabar el enorme esfuerzo y trabajo que allí se realiza destacando, entre otros, la creación del Centro de Estudios Vacceos "Federico Wattemberg".

A pesar de la poca información y la investigación parcial, algunos elementos han calado muy hondo en la sociedad que, actualmente, habita en "territorio vacceo". Ello ha provocado que el "colectivismo vacceo", el consumo del vino, el problema de límites territoriales y el origen celta (tomando como ejemplo el caso de los "vacceos cavaliers"), entre otros, aparezcan retratando la sociedad actual, aunque ya veremos si con el mismo significado.

a.

$$
\text { “Colectivismo vacceo". }
$$

Uno de los rasgos más empleados en la caracterización de los vacceos, o quizá el que más ríos de tinta han provocado, es el sistema de producción denominado "colectivismo agrario". La única referencia histórica a este sistema agrícola es de Diodoro de Sicilia, el cual indica en su Bibliotheca Histórica: "Entre los pueblos vecinos (de los celtíberos), la organización más curiosa es la de los llamados vácceos; cada año dividen la tierra entre ellos y la cultivan; consideran la cosecha propiedad común y entregan su parte a cada uno, y han establecido la pena de muerte para los agricultores que sustraen alguna cosa" (Diodoro V 34,3) ${ }^{5}$.

Una de las últimas revisiones críticas de este sistema agrícola se debe a M. Salinas ${ }^{6}$, quien pone en tela de juicio la existencia de una propiedad colectiva para todo el pueblo vacceo; éste indica que las pruebas sobre las que reposa la teoría del régimen comunal vacceo no pueden darse por válidas.

En primer lugar, la referencia del texto de Diodoro y los testimonios pertenecientes a la misma época parecen mostrar que la realidad reflejada por el texto diodoreo era algo excepcional y que la propiedad privada

de Estudios Vacceos Federico Wattenberg). Valladolid; SANZ MÍNGUEZ, C. y ROMERO CARNICERO, F. (eds.) (2007): En los extremos de la región vaccea (Caja España). León.

4 SANZ MÍNGUEZ, C., VELASCO VÁZQUEZ, J., CENTENO CEA, I., GALLARDO MIGUEL, M.A. y GARRIDO BLÁZQUEZ, A.I., (2003); “El Centro de Estudios Vacceos 'Federico Wattenberg' y el Proyecto Pintia. Bases para la protección, investigación y divulgación del patrimonio cultural vacceo”,en Sanz Mínguez, C. y Velasco Vázquez, J. (eds.); Pintia. Un oppidum en los confines orientales de la región vaccea. Investigaciones arqueológicas vacceas, romanas y visigodas (1999-2003). (Universidad de Valladolid). Valladolid, pp.251-278.

5 Traducción y notas de Juan José Torres Esbarranch. Biblioteca Clásica de Gredos, 2004 6 SALINAS DE FRÍAS, M. (1989), "Sobre las formas de propiedad comunal de la cuenca del Duero en época prerromana" en Veleia, Vitoria, pp. 103-110 
había relegado la propiedad comunal a un lugar secundario ${ }^{7}$ Además, en ningún lugar del texto se afirma que se reparta entre los campesinos todo el producto y que no exista una apropiación nobiliaria de una parte de la cosecha; es decir, la propia exégesis, de admitir como válido el testimonio, podría interpretarse incluso en un sentido opuesto ${ }^{8}$.

El agerper extremitatem mensura comprenhensus, nos es conocido por la cita de Frontino (Th., 1-2), quien nos dice que es el sistema romano característico del suelo tributario. Implantado por Augusto se basaría en hacer de cada ciudad estipendiaria una unidad de recaudación estableciendo un perímetro de los territorios urbanos, constatado epigráficamente a través de los términi, sobre los que establecería un impuesto basado en la tierra. Las divisiones parcelarias individuales y sus propietarios no interesaban a la administración central. Parece que no hubo centuriación ni asignación de tierras a colonos, por lo que en principio cabría esperar una cierta continuidad de los sistemas de ocupación indígenas o al menos una evolución paulatina hacia los sistemas romanos', sin embargo, que supongamos una continuidad de los sistemas de ocupación indígenas no nos indica cómo serían dichos sistemas.

Las excavaciones de Blas Taracena en Langa de Duero, quizá Segontia Lanka, localizaría un edificio de grandes dimensiones, dentro del cual se encontraron un gran número de herramientas agrícolas, interpretado, de manera algo forzada, como un almacén comunal ${ }^{10}$. Sin embargo ello solo verificaría que había útiles de labor que eran propiedad de la comunidad (también se hallaron en las casas particulares, que serían de propiedad privada) y, como mucho, que había trabajos que se realizaban colectivamente, como las rozas, pero de ninguna manera que las tierras, y específicamente las de labor, fuesen de propiedad comunal ${ }^{11}$. Los hallazgos arqueológicos parecen apoyar la existencia de propiedad privada; el bronce de Contrebia del 15 de mayo del año 87 a. C. muestra que en el territorio de estas ciudades del valle del Ebro había terrenos que eran unos de propiedad pública y otros de propiedad privada; estos últimos podrían comprarse o venderse libremente

7 SALINAS DE FRÍAS, M. (1989), op. cit. p. 106; SALINAS DE FRÍAS, M., (1990b); “El colectivismo agrario de los vacceos: una revisión crítica", Actas del I Congreso de Historia de Zamora (Zamora, 1988) vol.II. (Instituto de Estudios Zamoranos "Florián de Ocampo"). Zamora, pp.429-435; SALINAS DE FRÍAS, M. (2004): "Los Vacceos en la Biblioteca Histórica de Diodoro de Sicilia", Conimbriga, 43, pp.47-62.

8 GÓMEZ FRAILE, J. Ma (2001): Los celtas en los valles altos del Duero y del Ebro. Memorias del seminario de Historia Antigua VIII. Universidad de Alcalá, p. 185

9 ARIÑO GIL, E., GURT ESPARRAGUERA, J.M. y PALET MARTÍNEZ, J.M. (2004): El pasado presente. Arqueología de los paisajes en la Hispania romana. (Ediciones Universidad de Salamanca. Publicacions i Edicions de la Universitat de Barcelona). Salamanca-Barcelona, p. 179.

10 Para una mayor información de las excavaciones consultar TARACENA, B. (1929) Excavaciones en las provincias de Soria y Logroño, MJSEA, no 103.

11 SALINAS DE FRÍAS, M. (1989), op. cit. p. 108 
incluso a otras comunidades ${ }^{12}$, indicándonos claramente la coexistencia de propiedad privada y colectiva. En la fase Soto II del poblado de Soto de Medinilla (Valladolid) se han localizado pequeñas construcciones de adobe cuadradas o rectangulares dentro de las cuáles se han hallado restos de cereal que parecen indicar que habían sido usadas como graneros; la pluralidad de estas construcciones y sus dimensiones relativamente pequeñas indican que nos encontraríamos ante depósitos de granos de propiedad privada perteneciente a unidades familiares. También se han localizado en el poblado de las Quintanas (Pintia) dentro del sector F1, varias casas de adobe y madera, de planta rectangular perteneciente a la segunda Edad del Hierro; en la casa identificada con la letra D se localizó un hoyo (fechable en el s. I a. C.) que contenía un conjunto de aperos, hasta ahora inéditos, y lo que parece debió ser la simiente reservada para una siembra próxima ${ }^{13}$. Todo ello unido a la gran importancia y extensión de la ganadería, que ya en torno al s. III a. C se ha constatado, implicaría un retroceso de las tierras dedicadas a cereal y de las formas de propiedad colectiva que pudieran articularse de las mismas. Sin embargo, no debemos negar la existencia de tierras de propiedad comunal de los grupos gentilicios, donde se ubicaran, por ejemplo, sus cementerios, dehesas, etc. ${ }^{14}$

Parece ser, por tanto, que solo poseemos el testimonio directo del colectivismo vacceo en las palabras de Diodoro, las cuales se remontarían a un momento en que la economía vaccea se hallaba en circunstancias excepcionales provocadas por la presión romana. Este sistema agrario se desarrollaría como una respuesta de emergencia para hacer frente a dichas necesidades de tipo económico y militar -lo que explicaría la pena capital impuesta a los infractores-, considerando que sólo un órgano como la ciudad-estado tenía el poder suficiente para realizarlo. Esta situación sólo afectaría a un porcentaje reducido de las tierras ya que la economía vaccea sería fundamentalmente agropecuaria, aunque el complemento agrario tuviese gran importancia ${ }^{15}$.

12 SALINAS DE FRÍAS, M. (1989), op. cit. p. 108

13 SANZ MÍNGUEZ, C., ROMERO CARNICERO, F., VELASCO VÁZQUEZ, J. e CENTENO CEA, I., (2003a); "Nuevos testimonios sobre la agricultura vaccea”, en Sanz Mínguez, C. y Velasco Vázquez, J. (eds.); Pintia. Un oppidum en los confines orientales de la región vaccea. Investigaciones arqueológicas vacceas, romanas y visigodas (1999-2003). (Universidad de Valladolid). Valladolid, p. 105; para mas información consultar ROMERO CARNICERO, F. (2007): "Esperando la labranza en Pintia. Aperos y grano en la bodega de una casa del siglo I a.C.”, en Romero Carnicero, F. y Sanz Mínguez, C. (eds.): En los extremos de la región Vaccea. (Caja España). León, pp.103-106.

14 Los cementerios vettones y los indicios de agrupación de tumbas por linajes podría indicar que la parcela ocupada por cada gentilitas o familia fuese propiedad común de la misma en SALINAS DE FRÍAS, M, (1982). La organización tribal de los vettones, Salamanca, pp. 67 y ss.

15 SALINAS DE FRÍAS, Manuel (1989), op. cit., pp. 110 
Sin embargo, la justificación o explicación de nuevas teorías políticas y económicas rescatarán dicho término dando lugar a construcciones de lo que el colectivismo agrario de Diodoro podría significar, construcción que, todavía podemos leer en obras actuales.

El primero en "rescatar" este concepto sería J. Costa (1845-1911) ${ }^{16}$; el cuál entenderá las palabras de Diodoro al pie de la letra. Costa identificaría literalmente la comunidad agraria vaccea con un sistema de socialismo agrario, integrándolo en la apología del comunismo primitivo de los pueblos prerromanos del interior, en oposición a la agricultura capitalista predominante de su época ${ }^{17}$. La alusión de Costa al granero público ${ }^{18}$ se refiere al "comunismo" vacceo, que también se dio en otros pueblos, y es típico de gentes en emigración que todavía no habían alcanzado su asiento definitivo $^{19}$. Sin embargo, las razzias de lusitanos y celtiberos en territorio vacceo de las que hay tantas menciones en las fuentes literarias presuponen una concentración de riqueza ganadera y de tierras en pocas manos ${ }^{20}$.

J. Caro Baroja corrige la asignación del comunismo por la de colectivismo, hablando de "cultura colectivista agraria del Valle del Duero Occidental" como una de las regiones geo-culturales de la Iberia antigua definida por tan particular régimen económico ${ }^{21}$. Caro defendería que el colectivismo sería algo extendido por Europa y Oriente siglos atrás aunque su puesta en funcionamiento no estaría reñida con la existencia de una estratificación social (los vacceos sortearían el trabajo de las parcelas y el reparto de las cosechas entre las grandes familias y linajes, bajo el control de los jefes del clan). El colectivismo agrario establecería un nuevo estadio en el proceso evolutivo de la práctica agrícola en el mundo antiguo caracterizado por el funcionamiento de explotaciones a gran escala y un alto rendimiento ${ }^{22}$. Basándose en esto, los etnólogos marxistas no dudarían en ver aquí una prueba del "comunismo primitivo", que debe encontrarse en los orígenes de toda sociedad. Este régimen implica la existencia de grandes graneros

16 COSTA Y MARTÍNEZ, J. (1983), Colectivismo agrario en España I-II. (Edición de C. Serrano; $1^{\text {a }}$ Edición 1898), Madrid, pp. 173- 175 (tomo II) y BLÁZQUEZ MARTÍNEZ, J.Ma . (1987); "Joaquín Costa y la historia de la España Antigua", Anales de la Fundación Joaquin Costa, 4, pp.119-137.

17 SÁNCHEZ MORENO, E. (1998-1999), “Agricultura vaccea: ¿Un topos literario? Ensayo de valoración" en Memorias de Historia Antigua XIX-XX, pp. 82

18 Alude a este término en su obra COSTA, J. (1917) La religión de los celtíberos y su organización politica y civil, Madrid.

19 Teoría también apoyada por autores como Ramos Loscertales y Maluquer.

20 BLÁZQUEZ MARTÍNEZ, J. M. (1987) "Joaquín Costa y la Historia de la España Antigua" en Anales de la Fundación Joaquín Costa, no 4, p. 131

21 CARO BAROJA, J. (1986), Ciclos y temas de la Historia de España. España Antigua (conocimiento y fantasía), Madrid

22 SÁNCHEZ MORENO, E. (1998-1999), op. cit. pp 82-83. 
y almacenes en que depositar las cosechas. ${ }^{23}$ Aún hoy en día, en las zonas en que lindaban los antiguos astures con los vacceos, han quedado formas curiosas de aprovechamiento de tierras en común, tales como la "rozada" en Aliste, o la "bouza" del concejo de la Cabrera que se han relacionado con las noticias de Diodoro. ${ }^{24}$

Autores como F. Wattemberg y C. Viñas Mey seguirán los mismos argumentos de Caro Baroja. M. Vigil defiende que el colectivismo agrario debe comprenderse dentro de las formas de propiedad colectiva características de los pueblos del centro peninsular, de acuerdo con la organización social de tipo tribal predominante en los mismos. Este pondría en relación directa los territorios del ager per extremitatem mensura comprehensus descritos por Frontino en el s. I d.C. con territorios que eran propiedad colectiva de toda una comunidad; y los únicos ejemplos que da Frontino son palentinos (territorio vacceo) y salmantinos (territorio fronterizo vacceo), los dos en las regiones centrales de la Península; lo que nos indicaría que los vacceos también tendrían un régimen de propiedad comunal". ${ }^{25}$

A. Domínguez Monedero"26 afirma que "la finalidad básica del sistema consiste en garantizar los medios económicos suficientes para que el grupo social pueda sobrevivir frente a grupos extraños, y frente a los condicionamientos geográficos, por medio del mantenimiento de una gran cohesión social, fundamentada en la cohesión común de las bases económicas, tanto agrícolas como pastoriles, y obtenida mediante la aplicación a la agricultura de los principios básicos que regulaban la vida de las sociedades pastoriles nómadas".

Todas estas opiniones dan por hecho que el trabajo colectivo vacceo se desarrolla dentro de sistemas sociales en los que la propiedad de la tierra también es colectiva. Por ello, tradicionalmente, se acepta que la romanización provocaría el paso del colectivismo de la tierra a la propiedad privada, al mismo tiempo que se disuelven los lazos gentilicios para dar paso a las relaciones de dependencia vertical ${ }^{27}$.

Como hemos podido ir observando, a pesar del avance en las teorías al compás de las nuevas investigaciones tanto de las fuentes históricas como arqueológicas, el ideario construido como justificación a un pensamiento,

23 CARO BAROJA, J. (1986), op. cit.p. 61

24 CARO BAROJA, J. (1986), op. cit. p. 63

25 Ya hemos citado que esta teoría ha sido rebatida por SALINAS DE FRÍAS, Manuel (1989), op. cit. p. 105

26 DOMINGUEZ MONEDERO, A. J. (1988), "En torno a algunos aspectos socioeconómicos de la cultura vaccea: Estado de la cuestión y nuevas aportaciones" en Caesarangusta $\mathrm{n}^{\circ}$ 65, pp. 61

27 Tesis apoyada por GONZÁLEZ-COBOS DÁVILA, A. M. (1989) Los vacceos. Estudio sobre los pobladores del valle medio del Duero durante la penetración romana. Universidad Pontificia de Salamanca, pp. 220-222 
como el defendido por Costa, que respondía, ideológicamente, a una época concreta de nuestra historia ha logrado perdurar en el pensamiento contemporáneo, con mucho más peso que los propios avances académicos.

b. $\quad$ El vino

Las fuentes clásicas señalan a Roma como la protagonista de la introducción del vino en el interior peninsular, adquirido mediante compra. Apiano (Iber. 54) nos relata la campaña de Lúculo contra la ciudad vaccea de Intercatia, el $151 \mathrm{a}$. C. indicándonos que dicha bebida era prácticamente desconocida en la Meseta: "Estaban además cansados por el insomnio en la guardia y por la falta de costumbre a los alimentos del país; pues al no haber vino, ni sal, ni vinagre, ni aceite y tener que alimentarse de trigo y cebada y mucha carne de ciervos y liebres hervida sin sal, eran presa de la disentería y muchos incluso murieron" 28

Sin embargo, las últimas investigaciones arqueológicas apuntan que el consumo del vino entre el pueblo vacceo puede fecharse en torno al s. VI a. C., e incluso se puede inferirse que desde finales del s. III a.C. y comienzos del s. II a.C. ya cultivaban la vid.

Para la Segunda Edad del Hierro contamos con testimonios claves que han dado un vuelco en lo que a consumo y producción de vino en la zona vaccea se refiere: pepitas de uva en Cauca y restos de vino en copas en la necrópolis de Pintia (Las Ruedas) ${ }^{29}$.

En una intervención arqueológica en 1989 en la calle Azafranal de Coca (Cauca) se localizaron diversas semillas de uva para el cultivo, entremezcladas con grano de cereal; el estrato al que correspondían se relaciona con los ataques de Lúculo y Pompeyo en el 151 a.C. y 74 a. C. respectivamente, lo que podría indicar que, al menos, desde finales del s. III y principios del s. II a. C. se cultivaba la uva, sin embargo no puede demostrarse que estas pepitas no llegaran a través del comercio, algo muy plausible ya que no tenemos constatados ni lagares ni análisis de las copas para ver su contenido ${ }^{30}$. También se localizaría, en 1999, un fragmento de kylix ático datado en el s. IV a. C. lo que, si pudiéramos constatar que éste fue empleado para el consumo exclusivo del vino, podría significar que en época anterior al s. III a. C. (fecha de las semillas) ya se consumía vino en Cauca y que este consumo sería de las élites que importaban el vino

28 ROMERO CARNICERO, F., SANZ MINGUEZ, C. y GÓRRIZ GAÑÁN, C. (2009) "El vino entre las élites vacceas de los más antiguos testimonios a la consolidación de su consumo" en SANZ MINGUEZ, C. Y ROMERO CARNICERO, F. (eds), El vino y el banquete en la Europa prerromana. Valladolid, pp 236-237

29 ROMERO CARNICERO, F., et allí. (2009) op. cit. p. 226

30 BLANCO GARCÍA, J. F. (2009), "Los inicios del consumo de uva y ¿del cultivo de la vid? En Cauca vaccea” en SANZ MINGUEZ, C. Y ROMERO CARNICERO, F. (eds.), El vino y el banquete en la Europa prerromana. Valladolid, pp 220-222. 
en vajillas de prestigio para, posteriormente, comenzar a producirlo ellos mismos. ${ }^{31}$

Por otro lado, en el cementerio de Pintia nos encontramos recipientes (principalmente copas y vasitos de factura local) que indicarían el consumo del vino. Los últimos análisis realizados a diversos vasos pintianos (principalmente copas) localizados en las necrópolis de las Ruedas y del barrio artesanal de Carralaceña, han detectado bebidas alcohólicas como el vino y la cerveza, lo que indicaría que desde, al menos el s. IV a. C. existía el consumo del vino junto con la cerveza, los cuales podrían estar mezclados con agua, miel...

En un principio serían las élites sociales las que consumirían el vino, seguramente de forma individual ${ }^{32}$, sin embargo la aparición de elementos como copas en tumbas de escaso ajuar guerrero parece indicar que aquéllas repartirían el vino entre individuos que estuvieran ligados a ellas por vínculos sociales de dependencia, clientela u hospitalidad, además de actuar como elemento vertebrador de las relaciones sociales, a través de rituales o ceremonias, tanto en banquetes funerarios como en ágapes domésticos, en las que su ingesta reforzaría la cohesión social y la práctica de la hospitalidad; prácticas no sólo compartidas por el pueblo vacceo. ${ }^{33}$

Como hemos citado anteriormente, no está claro que se cultivara la vid durante este periodo, lo que sí parece claro es que, al menos en unos primeros momentos, el caldo llegaba a las elites a través del comercio. Una de las rutas posibles es siguiendo la ruta de la Plata, no obstante, la identificación de cerámicas áticas en los limites orientales de la Meseta Sur y de cerámicas ibéricas en yacimientos vacceos al sur del Duero, hacen plausible una ruta alternativa desde el sureste que condujera los caldos producidos en el mundo ibérico desde el s. VII a. C., hacia las tierras del interior. Con todos los datos que hemos recogido, parecería posible que la viticultura y la vinificación bien pudieron sobrevenir en los momentos inmediatamente anteriores a la conquista romana, para consolidarse a partir de esas fechas, incrementándose su producción desde los primeros siglos de nuestra era. ${ }^{34}$

Regresemos al presente. La gran importancia del vino en las actuales clases altas y pudientes ha provocado un cambio en las formas de consumir el vino, muy lejos de aquellas tabernas y tascas de no hace tanto. Además, medios de comunicación y diversos tipos de propaganda están creando una "cultura del vino".

Quizás será por este "fenómeno" por el cual historiadores y antropólogos han comenzado a desarrollar numerosas investigaciones como la Arqueología del vino, de hecho dentro del Proyecto Pintia se ha desarrollado

31 BLANCO GARCÍA, J. F. (2009), op. cit. pp. 222-223

32 DOMÍNGUEZ MONEDERO A. J. (1995), op. cit. p. 61

33 ROMERO CARNICERO, F., et alli. (2009) op. cit. p. 247

34 ROMERO CARNICERO, F., et alli. (2009) op. cit. pp. 249. 
entre 2005 y 2008 una línea de investigación sobre la Arqueología del vino favorecido por el convenio firmado entre la Universidad de Valladolid y Bodegas y viñedos Carraoviejas, que incluye un programa de becas. ${ }^{35}$ Además, prácticamente la totalidad de las bodegas de la zona del Duero, que cuenta con denominación de origen, entroncan el consumo del vino al pueblo vacceo: la Bodega Emina (Valbuena de Duero, Valladolid), convertida también en centro turístico, posee un museo que alude al origen vacceo del vino de la zona, aunque no los considera los primeros productores, siendo éstos los monjes de Santa María de Valbuena. Las bodegas Emilio Moro, localizadas en Pesquera del Duero (Valladolid) también hacen a los vacceos los primeros consumidores de este caldo, identidad de la sociedad actual, heredera directa de los mismos vacceos, y del mismo Pesquera del Duero, siendo la cultura del vino una de las formas de vida de la zona.

Numerosas reuniones científicas y exposiciones, muchas de ellas patrocinadas por bodegas han dado lugar a diversas publicaciones tanto científicas como divulgativas. Al tiempo, la cerveza ha ido ganando terreno entre las bebidas habituales gracias a su precio más asequible, al igual que ocurriera en la Antigüedad ${ }^{36}$.

\section{c. Límites territoriales: el caso salmantino}

Las primeras referencias a Salmantica las encontramos en Polibio (III, 14, 9) y Livio $(21,5)$, los cuales la adscriben al pueblo vacceo durante la expedición de Aníbal en el 220 a. C., cuando llega hasta Arbulaca. Sin embargo, a mediados del s. II d. C., Ptolomeo (II, 5-7), en una enumeración de las ciudades vetonas, incluye a Salmantica.

Estas referencias son el inicio de diversas investigaciones para verificar la adscripción de la ciudad a un pueblo u otro.

Según las teorías basadas en la llegada de diversas oleadas de pueblos celtas a la Península podemos ver, como en la oleada celta denominada belga, en torno al 600 a. C., los vacceos, después de escindirse de un grupo mayor, se asienta en el valle medio de Duero sobre el sustrato indígena y de otras oleadas anteriores, de esta forma, se lleva a cabo la conquista de Salmantica por dichos vacceos ${ }^{37}$. Así se explica que en las noticias de Polibio y Livio, Salmantica sea señalada como vaccea. Sin embargo, a la llegada de los romanos, la situación cambiaria ya que estos restituirían el territorio originario vetón para debilitar la fuerza del mundo celtibérico,

35 ROMERO CARNICERO, F., SANZ MINGUEZ, C. y GÓRRIZ GAÑÁN, C. (2009) "El vino entre las élites vacceas de los más antiguos testimonios a la consolidación de su consumo" en SANZ MINGUEZ, C. Y ROMERO CARNICERO, F. (eds), El vino y el banquete en la Europa prerromana. Valladolid, pp 239

36 SANZ MINGUEZ, C., ROMERO CARNICERO, F., GÓRRIZ GAÑÁN, C. y DE PABLO MARTÍNEZ, R., (2009)"El pasado en el presente" en El vino y el banquete en la Ribera del Duero durante la Protobistoria, Vaccea Monografías, Valladolid, pp. 101-103.

37 SÁNCHEZ MORENO, E. (1995), op. cit., pp. 477 
al cual pertenecía el pueblo vacceo (teoría también de la época, ya que actualmente la investigación se decanta por diferenciar claramente el mundo celtibérico del vacceo ${ }^{38}$ ), por ello, en las noticias posteriores de Ptolomeo, Salmantica aparece como vetona. Diversos autores defienden esta teoría: J. Maluquer y A. Taracena indican que los vetones procederían de una oleada indoeuropea anterior a la de los vacceos, siendo acorralados por éstos hasta que los romanos restablezcan sus antiguas fronteras en beneficio de los vetones; J. Ma Blázquez retoma la interpretación, gestada en Bosch Gimpera, del expansionismo vacceo de raíz celtibérica - etnia derivada del grupo de celtas belgas - sobre los vetones hasta el punto de someterlos territorial y culturalmente; al igual que Lomas, el cual piensa en una hegemonía de vacceos sobre vetones, incluso como élite aristocrática o minoría dirigente que se impone sobre los vetones, con un horizonte cultural que le es propio, el segundo nivel de Cogotas; así lo testimoniarían, por ejemplo, las ricas tumbas de guerreros de La Osera o Las Cogotas ${ }^{39}$.

Sánchez Moreno descarta esta teoría indicando que se aplica incorrectamente el concepto de territorio y dominio político para estos momentos y pueblos, en lugar de hablar de un área variable de expansión e influencia. Además resalta la inconveniencia de dar validez y acomodar la información de momentos tardíos (Livio, Ptolomeo...) para períodos muy anteriores como el s.III a. C; acentuada en este caso por el hecho de utilizar con una misma intencionalidad a dos fuentes cronológica y conceptualmente bien distintas. Por todo ello la cuestión de la ocupación del territorio norte de los vetones por parte de los vacceos hasta Salmantica al menos debe ser entendida más como un asunto de reorganización de fronteras al sur del Duero, siguiendo una estructuración natural de los límites y fronteras romanos.

Esta controversia historicista se ha reflejado en la actualidad en la ciudad de Salamanca. En una de las entradas a la misma, en el barrio de El Arrabal (curiosamente localizada en la entrada meridional a la ciudad), se localiza un cartel que da nombre a una de las numerosas rotondas con las que cuenta la ciudad: en él podemos leer "Glorieta de vacceos y vettones", reflejando las teorías anteriormente citadas e indicando que, según las fuentes clásicas, Salamanca, o más bien Helmantica perteneció a ambos pueblos. Un debate historiográfico que debiera estar superado y sin embargo se proyecta -al menos viariamente- en la identidad moderna de la ciudad del Tormes.

d. ¿Son celtas los vacceos? El caso de los "vacceos cavaliers"

El origen de los pueblos prerromanos, como los vacceos, ha sido un tema de discusión desde finales del s. XIX; la ya superada teoría de la existencia de diversas oleadas celtas que se asentaron en suelo peninsular

38 Para más información consultar BURILLO MOZOTA, F. (2007), Los Celtíberos. Etnias y estados. Crítica, pp. 242-247 [1 $1^{\text {a }}$ edición de 1998]

39 SÁNCHEZ MORENO, E. (1995), op. cit., pp 484-485 
todavía se hace sentir un numerosos estudios y no digamos en el imaginario popular. Un ejemplo de ellos es el caso de los vacceos cavaliers ${ }^{40}$, franquicia de rugby creada en 2009, cuya historia se entronca directamente con la idealización del celta. Ellos mismos nos indican su origen de la forma siguiente:

"Hacia el año 650, también antes de la Era Común, otras oleadas celtas, de las denominadas Belgas, llegaron al Valle del Duero. En esta última oleada, compuesta por varias ramas celtas, nos vamos a centrar para el presente articulo, en la rama de los Bellovacos, bello-vacci, o bello-vacceos, que es lo mismo, dicho por diferentes investigadores. Entre estos bello-vacceos, uno de sus componentes, los bellos o belos, se asentaron junto a las riberas oeste del Ebro y del Jalón. Otros como los tittos, ocuparon el nacimiento del Tajo, los arévacos el Alto Duero y los vacceos ocuparon el valle Medio del Duero. Esta segunda oleada belga fue muy numerosa, se extendió también hacia otras zonas de lo que boy es la Península Ibérica. En la zona que comentaba al principio, fueron los vacceos los que se impusieron y mezclaron con los elementos indígenas preindoeuropeos y con los celtas de la primera oleada. Todos ellos aglutinados pasaron a formar parte de lo que histórica y arqueológicamente se ha denominado "Reino Vacceo", que perduró desde el 650 al 220 antes de nuestra era común. En esos años, se celtizaron las ciudades que quedaban propiamente indígenas, tras la primera oleada celta y hasta la llegada del ejército cartaginés. Las ciudades que fundaron los celtas de la segunda oleada, se caracterizaban porque muchas de ellas acababan con la terminación celta de "briga", sujeta a varias interpretaciones, pero sin duda celta. Algunas de las más conocidas y dentro del área de influencia vaccea fueron: Lacóbriga (Carrión de los Condes, Palencia); Amallóbriga (Tiedra, Valladolid); Arcóbriga (Arcos de Jalón, Soria); Deobriga (Miranda de Ebro) y otras. Durante los 430 años que duró la independencia vaccea, se estableció una confederación de pueblos desde ciudades como Althía (en la provincia actual de Toledo) hasta Arbocala (Zamora), desde Numancia (En Soria) hasta Pallantia (Palencia). Dicha confederación fue bello-vacci o bellovaca y continuaron relacionándose entre sí, con un mismo idioma y ocupando los centros más importantes cerealísticos que coincidian con las ciudades más pobladas y a la vez. ocupando las entradas a la Meseta que aún siendo menos productivas les servian de proteción. Los más belicosos, se asentaron en las zonas fronterizas, donde fundaron las ciudades "brigas". Los más pacificos, como los celtas descendientes de la primera oleada y los indigenas preindoeuropeos, labradores y ganaderos ocuparon el centro de su vasto territorio. Entre todos el "Reino Vacceo", sobrepasó el millón de habitantes, que no es poco, para la época".

Como hemos podido leer, serán ellos mismos los que indiquen las características que querían imprimir en su organización: "unión territorial" será la más importante. Sin embargo, esta, sin una génesis que la englobara quedaría incompleta, en ese momento aparecen los vacceos. Las cronologías

40 Franquicia castellanoleonesa de rugby, creada en el 2009, www.vacceoscavaliers.com . En ella encontramos diversa información tanto de los jugadores de la misma, las fechas en las que se juega algún partido de rugby, la historia de dicha franquicia; además se pueden ver en línea los partidos jugados en el momento. Incluso una de las figuras del deporte, Michael Robinson alaba la creación de la misma. [consultado el 28 de febrero; 18:00 horas] 
que manejan están claramente relacionadas con la teoría de las oleadas celtas $^{41}$; sin embargo, será la fecha del 220 a. C., coincidente con la llegada cartaginesa a territorio vacceo, la que se nos descuelga un poco ya que no parece que esta incursión provocara cambio alguno en la organización vaccea. En mi opinión, este último dato podría estar mostrando, exclusivamente, la primera vez que una "potencia extranjera" entra en territorio vacceo.

Una vez que los celtas se asentaron en territorio vacceo parece que llevaron a cabo diversas presiones para expansionarse; las palabras imposición y mezcla utilizadas en el texto no nos dejan lugar a duda. Numerosas investigaciones, como explicación al problema fronterizo que protagoniza la ciudad de Salamanca ${ }^{42}$, han defendido que los recién asentados pueblos vacceos presionarían contra territorio vetón hasta acorralarlos en las montañas, recalcando así la característica propia de los pueblos celtas: estos son, ante todo, nobles guerreros (caracterización de los celtas típica del s. XX) ${ }^{43}$.

Las constantes alusiones al ficticio "Reino Vacceo" no hacen más que apoyar la idea de unidad territorial que no parece coincidir, en demasía, con la organización territorial vaccea basada en un conjunto grandes oppida centrales que dominarían un territorio de gran amplitud y que mantendrían relaciones con otros oppida.

La creación de ciudades, a la que el texto hace alusión, sigue en consonancia con las clásicas y desfasadas teorías de las oleadas celtas. Numerosos lingüistas, ya desde finales del s. XVIII, intentaron justificar la existencia de este pueblo celta que se expansionó por toda Europa, sin embargo, en la actualidad sólo se defiende la existencia de influencia celta, sin movimientos poblacionales ${ }^{44}$.

De igual forma, la búsqueda sistemática de una lengua común, fue el objetivo de estos "investigadores celtas". No hay que olvidar, que la lengua y escritura son uno de los pilares básicos para crear una identidad común. Sin embargo, en cuanto a territorio vacceo se refiere, sólo podemos decir que la única prueba de escritura localizada es a través de algunas tesseras de hospitalidad (como la de Palenzuela), ya en zona fronteriza con territorio celtíbero, cuya escritura si está constatada.

41 La historiografía sobre estas oleadas celtas en SANCHEZ MORENO, E. (1995) op. cit 42 Vide supra

43 AgUILERA DURÁN, T. (2010), "Arqueología de un mito. Celtomanía y Celtoescepticismo", en Desperta Ferro. Historia militar y politica de la Antigüedad y el Medievo, no 2 (noviembre 2010), p. 7

44 RUIZ ZAPATERO, G. (2010): "Roma conquistó la Galia Y Astérix y Obélix conquistaron el mundo. Desenmarañando a los celtas", en Cardete del Olmo, M.C. (ed.): La Antigüedady sus mitos. Narrativas históricas irreverentes. (Siglo XXI). Madrid, pp.97-114. 
La constante referencia a la belicosidad del pueblo se enlaza directamente con la visión del bárbaro como individuo dedicado a la guerra constante por las fuentes clásicas ${ }^{45}$; la contraposición entre los vacceos, guerreros que controlan las fronteras, y los celtas llegados en oleadas anteriores e indígenas preindoeuropeos dedicados a la agricultura y la ganadería está íntimamente desarrollado con la creación de una imagen "guerrera" tan acorde con el rugby. Además, la existencia de los "caballeros" en el nombre de la franquicia, relaciona directamente esta imagen guerrera con la de los jinetes vacceos, tan temidos por las tropas romanas ${ }^{46}$.

El escudo del equipo deportivo también está pensado para la identificación con los vacceos; se trata de un escudo, ovalado haciendo referencia al balón de rugby, sobre fondo rojo carmesí del pendón castellano, una representación simbólica "celta" del caballo, el bien más preciado de los vacceos, utilizado para la labranza, el transporte, la guerra y desde el punto de vista ritual y montura de los cavaliers o jinetes guerreros. En los costados del escudo el castillo símbolo del reino de Castilla, como alusión al origen geográfico del equipo impulsor de la franquicia. También se buscó una tipografía celta para el nombre de la franquicia con mayúsculas ribeteadas con símbolos celtas.

\section{CONCLUSIÓN}

Llama la atención la existencia, en el imaginario colectivo, de algunos elementos vacceos claramente diferenciados capaces de ser absorbidos por la población actual para convertirlos en elementos identitarios. Sumados a los elementos anteriores tenemos asociaciones culturales, grupos "tribales" de reconstrucción histórica, menciones gastronómicas, blogs personales... que hacen alusión, de una forma u otra al pueblo vacceo.

La Asociación Cultural Vacceos ${ }^{47}$; el origen del pueblo de Matapozuelos (Valladolid) ${ }^{48}$; el anuncio del lechazo ${ }^{49}$ atribuyéndolo al pueblo vacceo; los grupos reconstruccionistas como el que participa en la recreación de las

45 MARCO SIMÓN, F. (1993): "Feritas Celtica: imagen y realidad del bárbaro clásico", en Gascó La Calle, F. y Falque Rey, E. (eds.): Modelos ideales y prácticas de vida en la Antigüedad clásica. (Universidad Internacional Menéndez Pelayo) Madrid, pp. 141-166.

46 Según Apiano [Apiano, Iber. 55; Apiano, Iber. 80-82]

47 http://www.vacceos.com/acvacceos/index.htm; creada en 1980 en el pueblo de Cigales, En ella se menciona a los vacceos como los primeros pobladores de la villa, desde el s. X a. C.

48 http://www.portal-uralde.com/historia.htm ; tienen como sus orígenes al pueblo vacceo, los cuales ya tenían la fiesta del 1 de mayo, el 1 de noviembre (Todos los Santos) y hacían hogueras durante la noche de San Juan

49 http://www.afuegolento.com ; con el sugestivo título de "Lechazo asado: del Vacceo al peta-zeta", (Aranda de Duero) 
Guerras del pueblo cántabro contra el invasor romano ${ }_{51}^{50}$; además de blogs personales... ${ }^{51}$

Todos estos ejemplos nos hacen reflexionar sobre los elementos de identidad del pueblo vacceo antes y después de la conquista romana y el consumo y reelaboración de su identidad en la actualidad. Es evidente que los elementos que han sido sometidos a esta reelaboración han sido elegidos premeditadamente para cumplir una función concreta; elementos culturales, económicos, ideológicos, populares... se entremezclan para cumplir con su objetivo.

El "colectivismo vacceo" fue reelaborado a través de una sola cita histórica para poder explicar el socialismo del momento; esta explicación a lo largo del tiempo fue, a su vez, reelaborada por diversos autores hasta la actualidad; quizás si este proceso no se hubiera dado, nadie se hubiera fijado en las palabras de Diodoro de Sicilia.

El tema del consumo del vino también es bastante controvertido. Los intereses de una actividad económica han logrado no sólo impulsar unas investigaciones, sino hacer de este consumo vacceo su signo de identidad, identidad enlazada con las "clases altas y pudientes" al igual que en la antigüedad estaba enlazada en "las elites sociales guerreras" hasta tal punto que han creado una "cultura del vino" propia de la zona del Duero, por cierto, con denominación de origen.

La existencia del cartel viario en la ciudad de Salamanca es, ante todo, muy curioso. Este, recién instalado en la vía, hace nos recuerda a un debate historiográfico académicamente superado.

El caso de los vacceos cavaliers llama mucho la atención. La existencia de esta franquicia quiere expresar su identidad, de hecho ellos mismos así lo declaran. No sólo la adscripción a una identidad territorial, de ahí la alusión en el escudo de los blasones del Reino de Castilla, sino la visión de que son herederos de aquellos bárbaros de enorme valor guerrero, cuya lucha era hasta el final, premisas de enorme transcendencia en un juego como el rugby, cuerpo a cuerpo, aunque basadas en la idealización de un bárbaro, que muy probablemente nunca estuvo en Hispania.

50 http://www.vacceos.net/index.html; se identifican con la tribu vaccea que, representando a su vez por otras trece legiones, se celebra desde el año 2001 en la localidad cántabra de Los Corrales de Valbuena, coincidiendo con el último fin de semana de Agosto y el primero de Septiembre. Ellos se describen de la siguiente forma: "nuestras zonas de asentamiento se extienden alrededor de de la Meseta Norte, a ambas orillas del río Duero y ocupan por completo lo que hoy son las provincias de Valladolid y gran parte de León, Palencia, Segovia, Burgos, Ávila, Salamanca y Zamora. Nos vestimos con capa negra y por supuesto, pieles. Y en lo referente a las armas, utilizamos una curiosa arte, por la cual se entierran todas las piezas (escudos, cascos, espadas...) hasta que se oxidan".

51 http://vacceo.blogspot.com; cuyo símbolo es uno de los utilizados por la web del yacimiento de Pintia 
Parece increíble que numerosos investigadores estén intentando esbozar aquellos elementos que pudieran ser utilizados como identitarios en el pueblo vacceo, y, sin embargo, a pie de calle, estos elementos estén plenamente conformados. Parece de fácil comprensión que teorías ya superadas perduren en aquellos elementos culturales, folclóricos... que se sustenten de ellas. Sin embargo, lo menos comprensible es que elementos nuevos, todavía sin aclarar en el ámbito científico-académico, ya se hayan convertido en identitarios, ejemplo claro es la utilización del vino. No es difícil pensar en su utilización política, económica, cultural... siendo el ejemplo más paradigmático el de Pintia. Su localización en la capital de la Comunidad Autónoma de Castilla y León provoca que se pueda dar una equivalencia entre territorio vacceo y la unidad administrativa actual, cuya capital Pintia pudiera ser la actual Valladolid. Sin embargo, cabe decir, que no todo el territorio de Castilla y León se encontraba habitado por vacceos; astures, turmogos, autrigones, cántabros, vetones... son otras de las identidades que poblaban dicho territorio, de las cuáles desconocemos sus reivindicaciones identitarias.

A pesar de todo, no podemos olvidar que gracias a todas estas reutilizaciones "de lo vacceo" estos siguen caminando por la campiña castellana. 
